\title{
Controlling Medical Costs: Perspectives From Financial And Nurse Executives
}

Paul J. Carruth, (E-mail: pcarruth@ selu.edu), Southeastern Louisiana University Ann K. Carruth, (E-mail: acarruth@ selu.edu), Southeastern Louisiana University

\begin{abstract}
The cost of healthcare in the U.S. is an issue of continuing concern for those who manage the economics of healthcare. Increasingly, as the system continues to undergo responsive changes in structure and processes, healthcare financial managers (HCFM) and Nurse Executives (NE) have emerged as an important part of healthcare reform. The purpose of this study is to compare the extent HCFMs and NEs believe various healthcare reform measures and cost containment strategies are effective. Eighty-four HCFMs, and 99 NEs from 36 states, comprised the sample for this study. Both groups agree that the majority of healthcare reform measures are moderately or very effective. In general, accounting practices that HCFMs and NEs have direct decision making authority over were deemed effective (i.e. accounting systems that reduce administrative costs). Three strategies not considered effective by both groups were restriction of coverage for various drug therapies, accounting systems that provide more accurate allocation of indirect/overhead cost; and increased physician accountability for cost containment. When comparing accounting systems, expense tracking, and cost shifting strategies, HCFMs were significantly more likely to rate cost shifting as effective than NEs. Acknowledging that HCFMs and NEs believe that accounting systems are responsive to healthcare reforms validates and contributes to the ongoing efforts of HCFMs and NEs to continue to use their expertise to maximize revenues, and minimize costs in order to provide competitive, caring patient care.
\end{abstract}

\section{INTRODUCTION}

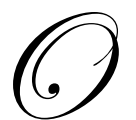

ver the last 30 years, the healthcare system has seen unprecedented changes in the economics of healthcare. Thirty years ago, physicians made exclusive decisions regarding when patients were admitted and discharged. Individuals, with employer-paid insurance, received services and the healthcare organization billed and received payment accordingly. The impetus for much of the change has been attempts at controlling spiraling costs. National debate during the early 1990s raised awareness of the industry's need for change. From the mid-1980s to present, declining inpatient census, shortened length of stay and significant changes in reimbursement have contributed to the closure or merger of many hospital units and the development of alternative treatment settings (Greenberg, 2001). The cost of healthcare in the U.S. is an issue of continuing concern for those who manage the economics of healthcare. Close to $\$ 2$ trillion is spent annually for healthcare (Centers for Medicare and Medicaid Services, 2004). Yet, without close monitoring and effective financial management, organizations will not be able to remain financially viable.

Healthcare financial managers and nurse executives are responsible for multimillion-dollar budgets, not unlike budgets of any other private corporation. Effective management of healthcare resources is important in keeping costs contained. Hospitals are the largest sector of health care expenditures. Nursing services represent the largest portion of the personnel budgets in most healthcare organizations. For example, on average, nursing accounts for more than $50 \%$ of hospital operating budgets (Caroselli, 1996). Therefore, hospitals are the primary target of efforts to curb rising costs in health care. 
Federal and state agencies, as well as private third party payers have developed reimbursement policies designed to encourage cost reduction by healthcare providers. As a result of a highly competitive cost containment environment, health care organizations have been forced to manage their resources more efficiently. Cost containment measures, such as lower length-of-stay averages and eliminating nonessential procedures are examples of maximizing reimbursement. Cost categories examined for potential cost savings include physician use of resources, patient expenses, organizational and operational expenses, supplier cost, and labor cost. Additionally, efforts at improved documentation have been shown to improve reimbursement. A trend that has emerged is an examination of who is responsible for financial viability of organizations. Increasingly, as the system continues to undergo responsive changes in structure and processes, healthcare financial managers (HCFM) and Nure Executives (NE) have emerged as an important part of the healthcare reform. There is increasing recognition that the collaboration between HCFMs and NEs has significant potential for providing collaborative leadership in health care delivery restructuring.

\section{PROBLEM STATEMENT}

Most research on healthcare reform focuses on (1) effectiveness of services or (2) impact on changes in documentation for reimbursement. Little is known about cost containment strategies employed by health care organizations providing a wide range of services. An exhaustive search of both accounting and nursing literature databases, no studies were found that examine the perceptions of health care financial managers or nurse executives concerning the impact of cost containment practices related to recent healthcare reform measures. Therefore, the purpose of this study is to examine trends in and compare perceptions of healthcare financial managers and nurse managers regarding the effectiveness of cost containment strategies in light of state and federal regulatory efforts and changes in the reimbursement policy of third party payers.

\section{OBJECTIVES}

Objectives of this study included the identification of and comparison of the perceived effectiveness of cost containment strategies used by Healthcare Financial Managers and Nurse Executives within healthcare organizations. Comparisons were made regarding perceptions of the effectiveness of cost control measures between these two groups.

\section{METHODS}

A descriptive survey was used to gain insight among healthcare financial officers and nurse executives across the United States and to examine perceptions of the impact of health care reform on cost containment and quality of patient care. A descriptive, comparative research design was employed for this study. Respondents were accessed through two sources: 617 Healthcare Financial Managers were accessed through the Healthcare Financial Management Association website and the 500 Nurse Executives were randomly selected with the assistance of a database from the American Organization of Nurse Executives. The sample consisted of 84 Healthcare Financial Managers and 99 Nurse Executives from 36 states. The survey questionnaire, Healthcare Reform Survey, developed by the investigators, consisted of 18 items. Packets contained a cover letter, the Healthcare Reform Survey, a Demographic Data Sheet and a stamped return envelope. To ensure protection of human rights, the research proposal was reviewed by the Institutional Review Board (IRB). Participation was voluntary and consent was assumed upon receipt of a returned questionnaire.

\section{INSTRUMENT}

The Healthcare Reform Survey was developed from an extensive review of the literature and interviews with healthcare financial managers and nurse executives. In general, survey items reflect the extent HCFMs and NEs believe that financial management, resource allocation, activity planning, and quality assurance have been effective at reducing healthcare costs. Subjects were asked to rate the effectiveness of each reform initiative as Not Effective (1); Moderately Effectively (2); or Very Effective (3). Content validity was determined by five content experts; two healthcare financial managers and three nurse executives. The questionnaire was pilot tested with twelve healthcare financial managers and nurse executives. Feedback was provided about the clarity of the questions, effectiveness of 
instructions, completeness of response sets, and time required to complete the questionnaire. Minor revisions to grammatical structure of items were subsequently made. Factor analysis with varimax rotation was undertaken to examine the underlying relationships of the items of the Healthcare Reform Survey and yielded three distinct factors: accounting systems; expense tracking systems; and cost shifting pattern. Nine items reflect Accounting Systems, six reflect expense tracking systems, and three reflect cost shifting. Cronbach's alpha was used for estimating internal consistency reliability. The internal consistency of the Healthcare Reform Survey- Effectiveness was $\propto=.87$.

\section{SAMPLE}

The survey respondents were 84 healthcare financial managers (HCFM) and 99 Nurse Executives (NE). The majority of HCFMs were male $(\mathrm{n}=59)$, had a mean age of 47.5 years $(\mathrm{SD}=6.9)$, and were involved in HCFM for an average of 19.8 years $(\mathrm{SD}=6.7)$. As shown in Table 1, the majority of HCFM were male, white, with areas of concentration in accounting or finance. In contrast, NE were likely women. This reflects that the majority of nurses are women in the United States. This sample of NE was highly educated, with the majority indicating a Master's Degree but not a MBA. When asked if HCFM had a family who had received healthcare in the last year, 79 (94.0\%) responded yes. The mean age for Nurse Executives was $51.63(\mathrm{SD}=7.09)$, had worked for the organization an average of 13.71 ( $\mathrm{SD}=10.26)$ years and held NE position an average of $7.32(\mathrm{SD}=5.99)$ years. Similarly, NEs had received healthcare in the last year $(n=95,96 \%)$. A striking contrast also exists in that the majority of NEs work for not-forprofit agencies.

Table 1: Professional Characteristics Of Healthcare Financial Managers (N=84) And Nurse Executives (N=99)

\begin{tabular}{|c|c|c|c|c|}
\hline \multirow{2}{*}{ Characteristics } & \multicolumn{2}{|c|}{ Healthcare Financial Managers } & \multicolumn{2}{|c|}{ Nurse Executives } \\
\hline & $\mathbf{n}$ & $\%$ & $\mathbf{n}$ & $\%$ \\
\hline Gender & & & & \\
\hline Male & 59 & 70.2 & 5 & 5.1 \\
\hline Female & 25 & 29.8 & 94 & 94.9 \\
\hline Ethnic Background & & & & \\
\hline White & 60 & 71.4 & 68 & 68.7 \\
\hline African American & 1 & 1.2 & 2 & 2.0 \\
\hline Hispanic & 3 & 3.6 & 1 & 1.0 \\
\hline Other & 20 & 23.8 & 28 & 28.3 \\
\hline Marital status & & & & \\
\hline Married & 72 & 85.7 & 72 & 72.7 \\
\hline Single & 5 & 6.0 & 5 & 5.1 \\
\hline Divorced & 5 & 6.0 & 2 & 2.0 \\
\hline Living with Significant Other & 1 & 1.2 & 6 & 6.1 \\
\hline Missing & 1 & 1.2 & 1 & 1.0 \\
\hline Educational background & & & & \\
\hline BA degree & 33 & 39.3 & 13 & 13.2 \\
\hline MBA & 32 & 38.1 & 1 & 1.0 \\
\hline Master's degree non business & 9 & 10.7 & 77 & 77.8 \\
\hline Doctorate & 2 & 2.4 & 3 & 3.0 \\
\hline Other & 6 & 7.1 & 3 & 3.0 \\
\hline Type of healthcare agency & & & & \\
\hline not for profit & 40 & 47.6 & 87 & 87.8 \\
\hline for profit & 17 & 20.2 & 6 & 6.1 \\
\hline consulting firm & 27 & 32.1 & 6 & 6.1 \\
\hline Areas of Concentration ${ }^{*}$ & & & & \\
\hline General Business & 22 & 26.2 & & \\
\hline Finance & 36 & 42.9 & & \\
\hline Healthcare management & 24 & 28.6 & & \\
\hline Accounting & 59 & 70.2 & & \\
\hline Economics & 5 & 6.0 & & \\
\hline Auditing & 7 & 8.3 & & \\
\hline Other & 13 & 15.5 & & \\
\hline
\end{tabular}

*Note: Some HCFM marked more than one area of concentration - Question not asked of Nurse Executives 
Respondents were asked to what extent they believed healthcare reform initiatives were effective for cost containment. Table 2 summarizes the responses for HCFM and NE. Responses are reported as not effective, moderately effective and very effective.

Table 2: Effectiveness Of Healthcare Reform Initiatives

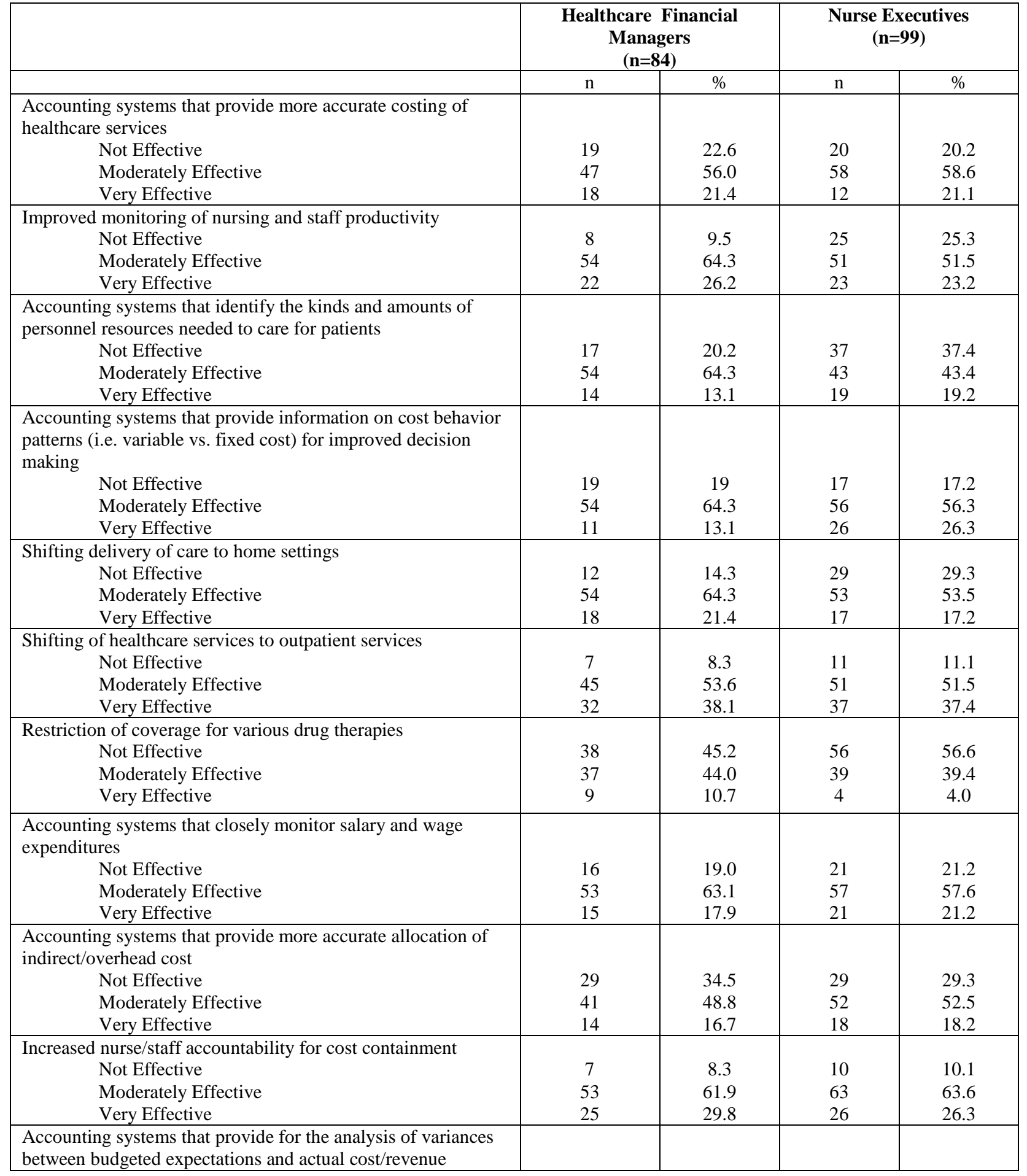




\begin{tabular}{|c|c|c|c|c|}
\hline $\begin{array}{l}\text { Not Effective } \\
\text { Moderately Effective } \\
\text { Very Effective }\end{array}$ & $\begin{array}{l}11 \\
54 \\
19 \\
\end{array}$ & $\begin{array}{l}13.1 \\
64.3 \\
22.9 \\
\end{array}$ & $\begin{array}{c}9 \\
58 \\
32 \\
\end{array}$ & $\begin{array}{r}9.1 \\
58.6 \\
32.3 \\
\end{array}$ \\
\hline $\begin{array}{l}\text { Accounting systems that closely monitor supply and } \\
\text { equipment costs } \\
\text { Not Effective } \\
\text { Moderately Effective } \\
\text { Very Effective }\end{array}$ & $\begin{array}{c}8 \\
57 \\
19\end{array}$ & $\begin{array}{c}9.5 \\
67.9 \\
22.6\end{array}$ & $\begin{array}{c}8 \\
49 \\
42\end{array}$ & $\begin{array}{c}8.1 \\
49.5 \\
42.4\end{array}$ \\
\hline $\begin{array}{l}\text { Reexamination of staffing patterns to address staffing needs } \\
\text { (i.e. mandatory overtime; cross training) } \\
\text { Not Effective } \\
\text { Moderately Effective } \\
\text { Very Effective }\end{array}$ & $\begin{array}{l}15 \\
53 \\
16\end{array}$ & $\begin{array}{l}17.9 \\
63.1 \\
19.0\end{array}$ & $\begin{array}{l}22 \\
50 \\
27\end{array}$ & $\begin{array}{l}22.2 \\
50.5 \\
27.3\end{array}$ \\
\hline $\begin{array}{l}\text { Increased physician accountability for cost containment } \\
\text { Not Effective } \\
\text { Moderately Effective } \\
\text { Very Effective }\end{array}$ & $\begin{array}{l}19 \\
39 \\
26\end{array}$ & $\begin{array}{l}22.6 \\
46.4 \\
31.0\end{array}$ & $\begin{array}{l}32 \\
43 \\
24 \\
\end{array}$ & $\begin{array}{l}32.3 \\
43.4 \\
24.2 \\
\end{array}$ \\
\hline $\begin{array}{l}\text { Improved utilization review systems that monitor the necessity } \\
\text { and appropriateness of care } \\
\text { Not Effective } \\
\text { Moderately Effective } \\
\text { Very Effective }\end{array}$ & $\begin{array}{l}10 \\
50 \\
26 \\
\end{array}$ & $\begin{array}{l}11.9 \\
59.5 \\
28.6 \\
\end{array}$ & $\begin{array}{l}10 \\
57 \\
32 \\
\end{array}$ & $\begin{array}{l}10.1 \\
57.6 \\
32.3 \\
\end{array}$ \\
\hline $\begin{array}{l}\text { Budgeting techniques that identify key performance areas and } \\
\text { track the cost of achieving specific goals } \\
\text { Not Effective } \\
\text { Moderately Effective } \\
\text { Very Effective }\end{array}$ & $\begin{array}{l}13 \\
51 \\
20 \\
\end{array}$ & $\begin{array}{l}15.5 \\
60.7 \\
23.8 \\
\end{array}$ & $\begin{array}{l}11 \\
56 \\
32 \\
\end{array}$ & $\begin{array}{l}11.1 \\
56.5 \\
32.3 \\
\end{array}$ \\
\hline $\begin{array}{l}\text { Accounting systems that assist in determining the kinds of } \\
\text { facilities, programs, equipment and medical specialties needed } \\
\text { to develop strategically } \\
\text { Not Effective } \\
\text { Moderately Effective } \\
\text { Very Effective }\end{array}$ & $\begin{array}{l}22 \\
42 \\
20\end{array}$ & $\begin{array}{l}26.2 \\
50.0 \\
23.8\end{array}$ & $\begin{array}{l}15 \\
49 \\
35\end{array}$ & $\begin{array}{l}15.2 \\
49.5 \\
35.4\end{array}$ \\
\hline $\begin{array}{l}\text { Accounting systems that reduce administrative cost (i.e. } \\
\text { expediting and simplifying insurance verification, billings, } \\
\text { collections, and payments) } \\
\text { Not Effective } \\
\text { Moderately Effective } \\
\text { Very Effective }\end{array}$ & $\begin{array}{c}9 \\
40 \\
35 \\
\end{array}$ & $\begin{array}{l}10.7 \\
47.6 \\
41.7\end{array}$ & $\begin{array}{c}6 \\
52 \\
41 \\
\end{array}$ & $\begin{array}{c}6.1 \\
52.5 \\
41.4\end{array}$ \\
\hline
\end{tabular}

Trends in responses were analyzed and compared. In general, HCFMs and NEs agree that the majority of healthcare reform measures were moderately effective. Healthcare reform measures deemed not effective tended to be those that the HCFM and NE had less control over, such as decreased coverage for various drug therapies and increased physician accountability. On the other hand, those measures that HCFMs and NEs have direct decision making over were deemed more effective (i.e. accounting systems that reduce administrative costs).

Three subscales, Accounting Systems, Expense Tracking, and Cost Shifting, were used to compare perceived effectiveness of cost containment measures between HCFMs and NEs. Table 3 outlines the means, SD, and independent $\mathrm{t}$-test values and $\mathrm{p}$ value for each comparison. Even though NEs felt accounting systems were more effective than HCFMs, there was no significant difference in mean scores. No differences between HCFMs and NEs existed in the expense tracking score. HCFMs were significantly more likely to feel that cost shifting was more effective in cost containment than NEs. 
Table 3 Comparisons Of Effectiveness Of Cost Containment Measures

\begin{tabular}{|c|c|c|c|c|}
\hline & $\boldsymbol{S}$ & $\boldsymbol{S}$ & $\boldsymbol{t}$ & $\boldsymbol{p}$ \\
\hline Accounting Systems & & & & \\
Healthcare Financial Managers & 18.19 & 3.97 & & \\
Nurse Executives & 19.09 & 4.41 & 1.41 & .162 \\
\hline Expense Tracking & & & & \\
Healthcare Financial Managers & 12.78 & 2.55 & & \\
Nurse Executives & 12.58 & 2.45 & .51 & .61 \\
\hline Cost Shifting & & & & \\
Healthcare Financial Managers & 6.02 & 1.41 & & \\
Nurse Executives & 5.61 & 1.44 & 1.91 & $.05^{*}$ \\
\hline
\end{tabular}

\section{Discussion}

This study examined the extent HCFMs and NEs believe healthcare reform initiatives are effective for cost containment given recent healthcare reform initiatives. HCFMs and NEs, leaders in their professional organization (Healthcare Financial Management Association and American Organization of Nurse Executives), from 36 states participated in the study. This nationwide study represents one of the few surveys of HCFMs and NEs and their perceptions of impact of reform initiatives to reduce the growing cost of healthcare in the country. This is significant because increasingly accounting officers work closely with nurse leaders in monitoring expenses in various types of healthcare organizations.

HCFMs and NEs are at the top levels of administration. As such they have had to help providers make significant adjustments in operating structure to accommodate the rapid shift from DRG reimbursement to managed care plans. The accounting systems in place in organizations are aimed at tracking and managing costs. Financial managers have been charged during the last decade with setting pricing for the services provided. Nurse Executives are relatively new to the responsibilities of cost centers and operating budgets. However, nursing is an essential source of revenue. The challenge for NEs is the fact that as clinical nurses they had little opportunity to engage in direct management of budgets. Therefore, many NEs are not formally trained in financial management and learn "on the job". Cost accounting has facilitated not only the pricing of services, but the communication of relevant cost separated into meaningful categories (Berger, 2002; Gapenski, 2002; Finkler, \& Kovner, 2000). This study examined two groups who control much of the budgetary expenditures in the healthcare facilities. They are in a unique position to understand if changes in cost containment have been effective.

HCFMs and NEs, in this study, felt most accounting systems were moderately or very effective. However, accounting systems that provide more accurate allocation of indirect cost was not rated overwhelmingly effective. This strategy may not be deemed effective because these costs, often utilities, telephones or purchasing services are allocated to the source department by a standard formula (Danna, 2006). Therefore financial managers may not see changes in the allocation within their control and therefore, not effective.

Other accounting strategies such as analyzing variances between expectations and actual cost/revenue, closely monitoring supply and equipment costs and reducing administrative costs were rated effective. Tracking/monitoring systems were also deemed effective by HCFMs and NEs. Specifically, budgeting techniques that identify key performance areas and track the cost of achieving specific goals was rated effective. Nurse executives and mid-level nurse managers are encouraged to examine variances in their budget on a regular basis. This action provides financial officers with an accurate record of activities on units in case the budget deviates from the financial performance expected.

Personnel account for the largest portion of the nursing budget. Accounting systems that monitor income and expenditures directly related to care are deemed effective. In healthcare, the challenge for managers is to deliver the best possible care with the best clinical outcomes without overspending for the services that need to be provided (Berger, 2002). Many issues have an impact on appropriate staffing of patient care. Simply changing the number of nurses per patient may not be the only or most cost effective strategy to provide safe and effective patient care 
(Bower, 2000). Few financial managers have the luxury of budgeting all resources needed at any given point in time. Quantifying decisions and how much these decisions cost involves knowing not only the kinds of personnel needed but also the kinds of supplies and equipment needed to efficiently provide care.

Healthcare organizations are dynamic, in a constant state of flux. One group that has experienced many changes are physicians who play an integral role in healthcare facilities' ability to stay financially viable. Without physicians, patients are not referred for services And without medically insured consumers who need services, organizations do not generate revenue. Physicians are usually considered the toughest group to train to appropriately document expenditures. They often do not work for the healthcare institution, they may be resistant to changes in documentation, and frequently do not understand that better documentation means better reimbursement (Berger, 2002). This may explain why, in this study, HCFMs and NEs, deemed attempts to increase physician accountability associated with cost containment less effective than other cost containment measures.

Of all strategies to reduce costs associated with healthcare, close to 50\% of HCFMs and over 50\% of NEs felt restriction of coverage for various drug therapies was not effective as a cost containment strategies. This may be explained by the fact that as new drugs are developed, escalating costs associated with their marketing may be a variable that is not easily managed in the model of delivery.

Influences from many sources impact fiscal viability. With limited resources and in a competitive market, HCFMs and NEs must evaluate personnel and material resources efficiently. In a consumer-driven system, employers, health plans, and insurance companies will increasingly rely on plan design to moderate cost increases (Altman and Levitt, 2002). In this study HCFMs and NEs felt that shifting delivery of care to home/outpatient settings was moderately effective. It is estimated that in addition to continued shifting of care, new health account models will attempt to address rising costs associated with monthly premiums and varying levels of point of service choice and tiered payments. What is not known is the cost to the families who care for family members. Future studies need to examine family intervention models that facilitate caregiver support which in turn theoretically reduces the need to return to the hospital during non-coverage periods (i.e. within a certain time frame after discharge from hospital).

A long term plan is needed to develop strategically. Accounting systems that determine kinds of facilities, programs, and equipment needed to develop strategically was more likely to be deemed moderately or very effective. It is understood that HCFMs and NEs have to understand the factors that affect the finances of the healthcare industry. This study attempts to describe similarities and differences between HCFMs and NEs. Acknowledging that HCFMs and NEs believe that accounting systems responsive to healthcare reforms are effective, validates and contributes to the ongoing efforts of HCFMs and NEs to continue to use their expertise to maximize revenues, and minimize costs in order to provide competitive, caring patient care.

\section{REFERENCES}

1. Altman, D. E. \& Levitt, L. 2002. The sad history of health care cost containment as told in one chart. Health Affairs. 21 (2), W83.

2. Berger, Steve. 2002. Fundamentals of Health Care Financial Management. San Francisco, CA: Jossey-Bass.

3. Bower, F. L. 2000. Setting the stage: An introduction to the principles. In Bower, F.L. (Ed.). Nurses taking the lead: Personal qualities of effective leadership. Philadelphia: W.B. Saunders Co., xiii-xiv, 1-13.

4. Caroselli, C. 1996. Economic awareness of nurses: relationship to budgetary control. Nurse Economics. 14, 292-298.

5. Centers for Medicare and Medicaid Services (2004, January 8). Press release: Health care spending reaches \$1.6 trillion in 2002. Retrieved July 27, 2006 from http://www.cms.hhs.gov/media/press/release.asp.

6. Danna, D. 2006. Principles of budgeting. In Roussel, L. (Ed) Management and Leadership for Nurse Administrators. Boston: Jones and Bartlett Publishers, 272-307.

7. Finkler, Steven \& Christine Kovner. 2000. Financial Management for Nurse Managers and Executives. $2^{\text {nd }}$ edition. Philadelphia: W.B. Saunders Company. 
8. Gapenski, Louis. 2002. Healthcare Finance: An Introduction to Accounting and Financial Management. $2^{\text {nd }}$ edition. Chicago IL: Foundation of the American College of Healthcare Executives.

9. Greenberg, M. 2001. Where will I go? Displaced nurses related their experiences. In: Feldman, H.R. (Ed.). Strategies for Nursing Leadership. New York: Springer Publishing Co., 301.

\section{NOTES}

